\title{
Quantitative analysis of the Kawase versus the modified Dolenc-Kawase approach for middle cranial fossa lesions with variable anteroposterior extension
}

\author{
Manjul Tripathi, MCh, ${ }^{1}$ Rama Chandra Deo, MCh, ${ }^{1}$ Ashish Suri, MCh, ${ }^{1}$ Vinkle Srivastav, BTech, ${ }^{1}$ \\ Britty Baby, MTech, ${ }^{1}$ Subodh Kumar, PhD, ${ }^{2}$ Prem Kalra, PhD, ${ }^{2}$ Subhashis Banerjee, PhD, ${ }^{2}$ \\ Sanjiva Prasad, PhD, ${ }^{2}$ Kolin Paul, PhD, ${ }^{2}$ Tara Sankar Roy, PhD, ${ }^{3}$ and Sanjeev Lalwani, MD ${ }^{4}$
}

\begin{abstract}
Departments of ${ }^{1}$ Neurosurgery, ${ }^{3}$ Anatomy, and ${ }^{4}$ Forensic Science and Toxicology, All India Institute of Medical Sciences; and ${ }^{2}$ Department of Computer Science and Engineering, Indian Institute of Technology Delhi, Hauz Khas, New Delhi, India
\end{abstract}

\begin{abstract}
OBJECT The surgical corridor to the upper third of the clivus and ventral brainstem is hindered by critical neurovascular structures, such as the cavernous sinus, petrous apex, and tentorium. The traditional Kawase approach provides a 10 $\times 5$-mm fenestration at the petrous apex of the temporal bone between the 5th cranial nerve and internal auditory canal. Due to interindividual variability, sometimes this area proves to be insufficient as a corridor to the posterior cranial fossa. The authors describe a modification to the technique of the extradural anterior petrosectomy consisting of additional transcavernous exploration and medial mobilization of the cisternal component of the trigeminal nerve. This approach is termed the modified Dolenc-Kawase (MDK) approach.
\end{abstract}

METHODS The authors describe a volumetric analysis of temporal bones with 3D laser scanning of dry and drilled bones for respective triangles and rhomboid areas, and they compare the difference of exposure with traditional versus modified approaches on cadaver dissection. Twelve dry temporal bones were laser scanned, and mesh-based volumetric analysis was done followed by drilling of the Kawase triangle and MDK rhomboid. Five cadaveric heads were drilled on alternate sides with both approaches for evaluation of the area exposed, surgical freedom, and angle of approach.

RESULTS The MDK approach provides an approximately 1.5 times larger area and 2.0 times greater volume of bone at the anterior petrous apex compared with the Kawase's approach. Cadaver dissection objectified the technical feasibility of the MDK approach, providing nearly 1.5-2 times larger fenestration with improved view and angulation to the posterior cranial fossa. Practical application in 6 patients with different lesions proves clinical applicability of the MDK approach.

CONCLUSIONS The larger fenestration at the petrous apex achieved with the MDK approach provides greater surgical freedom at the Dorello canal, gasserian ganglion, and prepontine area and better anteroposterior angulation than the traditional Kawase approach. Additional anterior clinoidectomy and transcavernous exposure helps in dealing with basilar artery aneurysms.

http://thejns.org/doi/abs/10.3171/2015.2.JNS132876

KEY WORDS Kawase; Dolenc; petrous; cadaver; quantitative; petrosectomy; skull base

$\mathrm{F}$ OR decades, the petrous part of the temporal bone has haunted skull base neurosurgeons and continues to do so. The depth of lesions, difficulties of approaches, and challenging neurovascular structures, e.g., brainstem and cranial nerves, have frightened neurosurgeons for decades, causing this area to have a reputation of a "No Man's Land." 17,18,22

Operative approaches to this area include clivectomy af- ter transcervical, transoral, extended transoral, subfrontal, transsellar-transcavernous, transsylvian, combined transsylvian and anterior subtemporal, and combined transsylvian and transpetrosal approaches. Approaches vary from pure extradural to intradural and combined ones., ${ }^{1,2,5}$ The variety of approaches proves that none is adequate for the various lesions in this area. The neurosurgical world owes Professor Takeshi Kawase for making us familiar

ABBREVIATIONS CN = cranial nerve; GSPN = greater superficial petrosal nerve; MDK = modified Dolenc-Kawase; $M M A=$ middle meningeal artery .

SUBMITTED December 28, 2013. ACCEPTED February 3, 2015.

INCLUDE WHEN CITING Published online April 3, 2015; DOI: 10.3171/2015.2.JNS132876.

DISCLOSURE The authors report no conflict of interest concerning the materials or methods used in this study or the findings specified in this paper. This manuscript is the result of research projects funded by the following extramural grants: Indian Council of Medical Research (ICMR), Ministry of Health and Family Welfare, Government of India; Department of Biotechnology, Ministry of Science and Technology, Government of India and BMBF, Germany-Indo-German Collaboration; and Department of Health Research, ICMR, Ministry of Health and Family Welfare, Government of India. 
with the anterior petrous bone with his extradural subtemporal transtentorial anterior petrosectomy approach, which avoids aerodigestive tract contamination and provides better exposure of the posterior cranial fossa. ${ }^{16,17}$ This approach provided an extradural corridor interposed between cranial nerve (CN) V and the CN VII/VIII complex, minimizing brain retraction.,16 Various surgeons have developed several modifications of the Kawase approach in a variety of permutations and combinations. ${ }^{16,17}$

Few studies are available for quantitative comparison of areas exposed by different operative approaches. ${ }^{6,7,14,20,21}$ We hereby describe a technique of the modified DolencKawase (MDK) approach, incorporating the surgical benefits of Dolenc's ${ }^{8}$ and Kawase's ${ }^{16}$ approaches, practiced by the senior author (A.S.). The MDK approach provides a larger area of exposure at the anterior petrous apex, maneuverability at Dorello's canal and the prepontine area with greater surgical freedom, and angulation via an extradural approach. This study is unique in that it uses 3D laser scanning of dry bones and quantitative mesh analysis of scanned polygonal data. The validity of the MDK approach is substantiated by computerized volumetric analysis of temporal bones and cadaver dissection, comparison with the Dolenc and Kawase approaches, and evaluation of clinical applications in 6 patients with a variety of lesions. This approach is helpful for large spheno-petroclival lesions with variable anteroposterior extension and basilar artery aneurysms. ${ }^{9}$

\section{Methods}

\section{Volumetric Analysis of Temporal Bones}

This approach includes laser scanning and volumetric analysis of intact bone followed by reanalysis after drilling the bones for the Kawase triangle and later by additional drilling of the MDK rhomboid. Twelve dry temporal bones were randomly selected from the bone bank of the De- partment of Anatomy (All India Institute of Medical Sciences) (Fig. 1 D1). These bones were laser scanned using Scanworks (Halyard Drive) (Fig. 1 L1). Three-dimensional scanned bone data were obtained in the form of point clouds. Geomagic Studio converts these point clouds into triangulated meshes. Fine processing of meshes was done with the aid of AutodeskMaya (Autodesk, Inc.) and ZBrush (Pixologic Inc.) (Fig. 1 M1). These meshes were evaluated for area and volume with the aid of MeshLab (version 1.3.2, Visual Computing Lab ISTI-CNR) (Table 1, Mesh 1).

The boundaries of the Kawase triangle were defined by the following landmarks: 1) the junction of the greater superficial petrosal nerve (GSPN) with the lateral border of the mandibular division of the trigeminal nerve (V3), 2) the lateral margin of the porus trigeminus, and 3) the anteromedial margin of the arcuate eminence (Fig. 1 D2, Fig. 2). The Kawase triangle was drilled using an electric diamond drill with the aid of a 3D microscope (OPMI Vario, Carl Zeiss; and 3D high-definition microscope camera, Sony) at uniform magnification (Fig. 1 D2). Drilled bones were rescanned (Fig. 1 L2), and volumetric analysis of the remaining bone was done as mentioned above (Table 1, Mesh 2) (Fig. 1 M2). The comparative evaluation of Mesh 1 and Mesh 2 provided the area and volume of the drilled portion of the bone (i.e., Kawase triangle) (Table 2).

The same bones (D2) were re-marked and drilled for the proposed rhomboid area (Fig. 1 D3), whose boundaries were defined as 1) the lateral margin of V3 after medial mobilization of the trigeminal nerve; 2) the bony surface, just lateral to petroclival ligament; 3) the arcuate eminence; and 4) the intersection of a line drawn along the axes of the GSPN and the arcuate eminence (Fig. 1 D3, Fig. 2). These bones were rescanned (Fig. 1 L3) and analyzed for area and volume (Fig. 1 M3) (Table 1, Mesh 3). The comparative evaluation of Mesh 1 and Mesh 3 provided the volumetric details of the drilled part of the bone (i.e., MDK rhom-

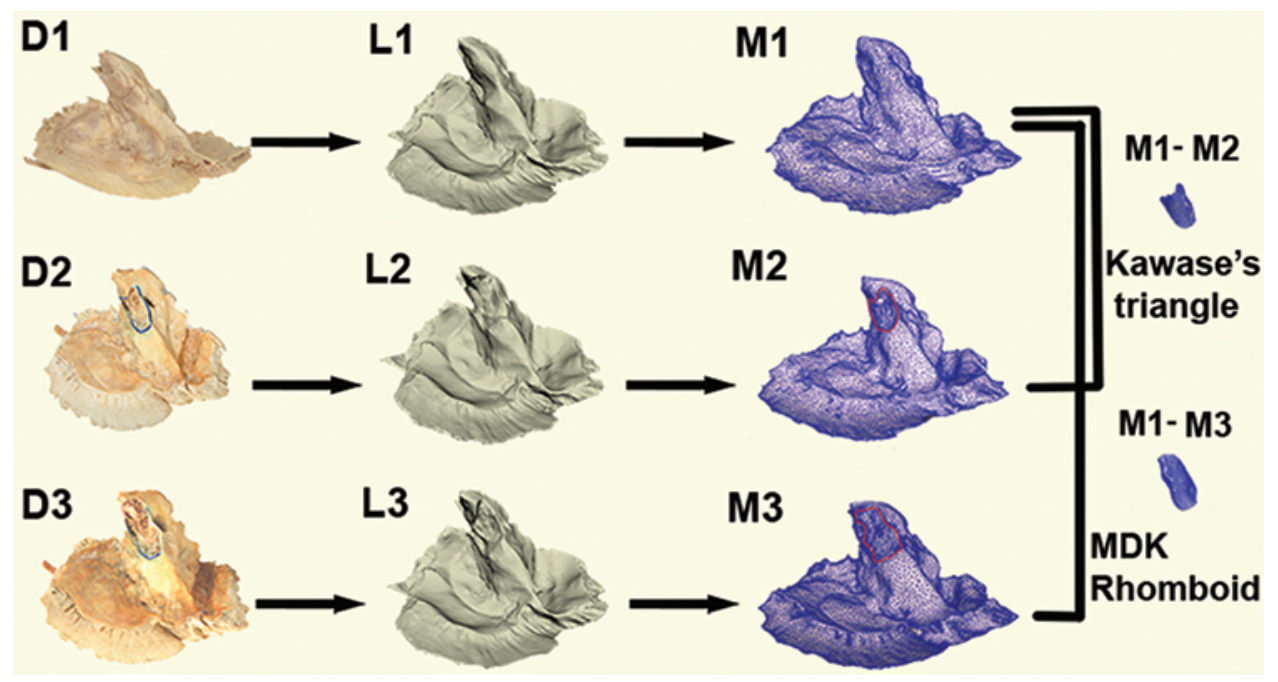

FIG. 1. Intact temporal bone (D1), corresponding laser scan (L1), and meshwork image (M1). Temporal bone after drilling of the Kawase triangle (D2), corresponding laser scan (L2), and meshwork image (M2) showing the drilled triangular part. Temporal bone after drilling of the MDK rhomboid area (D3), corresponding laser scan (L3), and meshwork image (M3). Arrows depict the sequential laser scanning and meshwork of the bone. $D=$ dry bone; $L=$ laser-scanned bone; $M=$ meshwork. Figure is available in color online only. 
TABLE 1. Area and volume of intact temporal bone (Mesh 1), remaining bone after drilling of Kawase's triangle (Mesh 2), and remaining bone after drilling of MDK rhomboid (Mesh 3 )

\begin{tabular}{|c|c|c|c|c|c|c|}
\hline \multirow{2}{*}{$\begin{array}{c}\text { Specimen } \\
\text { No. }\end{array}$} & \multicolumn{2}{|c|}{$\begin{array}{l}\text { Intact Dry Temporal } \\
\text { Bones (Mesh 1) }\end{array}$} & \multicolumn{2}{|c|}{$\begin{array}{c}\text { Temporal Bones After Drilling of } \\
\text { Kawase's Triangle (Mesh 2) }\end{array}$} & \multicolumn{2}{|c|}{$\begin{array}{c}\text { Temporal Bones After Drilling of } \\
\text { MDK Rhomboid (Mesh 3) }\end{array}$} \\
\hline & Area $\left(\mathrm{mm}^{2}\right)$ & Vol $\left(\mathrm{mm}^{3}\right)$ & Area $\left(\mathrm{mm}^{2}\right)$ & Vol $\left(\mathrm{mm}^{3}\right)$ & Area $\left(\mathrm{mm}^{2}\right)$ & Vol $\left(\mathrm{mm}^{3}\right)$ \\
\hline 1 & $12,594.606$ & $96,866.102$ & $12,400.056$ & $96,192.554$ & $12,036.646$ & $94,687.316$ \\
\hline 2 & $15,301.513$ & $129,188.734$ & $15,164.803$ & $128,704.728$ & $14,831.553$ & $127,544.823$ \\
\hline 3 & $12,907.796$ & $101,742.586$ & $12,719.166$ & $101,186.807$ & $12,385.666$ & $100,080.641$ \\
\hline 4 & $14,709.261$ & $126,224.195$ & $14,413.121$ & $125,370.967$ & $14,006.481$ & $124,071.684$ \\
\hline 5 & $13,340.863$ & $105,108.383$ & $13,084.133$ & $104,312.414$ & $12,805.203$ & $103,360.086$ \\
\hline 6 & $14,821.771$ & $126,969.266$ & $14,517.671$ & $125,630.618$ & $14,289.041$ & $125,189.324$ \\
\hline 7 & $14,022.294$ & $113,722.547$ & $13,734.974$ & $112,930.782$ & $13,262.984$ & $111,462.477$ \\
\hline 8 & $16,521.176$ & $149,546.203$ & $16,095.026$ & $148,467.615$ & $15,480.746$ & $146,629.854$ \\
\hline 9 & $16,223.099$ & $145,045.938$ & $15,849.349$ & $144,281.776$ & $15,385.108$ & $142,841.501$ \\
\hline 10 & $12,042.714$ & $91,733.883$ & $11,790.814$ & $90,991.685$ & $11,454.554$ & $89,876.364$ \\
\hline 11 & $13,557.831$ & $113,621.258$ & $13,333.121$ & $112,959.172$ & $12,950.181$ & $111,689.021$ \\
\hline 12 & $12,878.767$ & $109,653.892$ & $12,589.637$ & $108,801.44$ & $12,499.917$ & $108,397.307$ \\
\hline Mean & $14,076.807$ & $117,451.916$ & $13,807.656$ & $116,652.547$ & $13,449.007$ & $115,485.867$ \\
\hline
\end{tabular}

boid) (Table 2). All the markings and drilling were done by the senior author (A.S.) to remove surgeon's error. All data were statistically analyzed using the Fisher exact test.

\section{Cadaver Dissection}

The ethics committee of the All India Institute of Medical Sciences approved the cadaver dissection work. Five fresh cadaver heads with no known brain pathology were dissected on both sides (10 specimens). All dissections were performed and recorded using a 3D microscope (OPMI Vario and 3D high-definition microscope camera). The drilling was done under fixed magnification (magnification factor 1.0; magnification $\times 7.08$ ). Each head was first treated via a traditional Kawase approach on one side and an MDK approach on the contralateral side. The ventral prepontine area was chosen as an area of interest

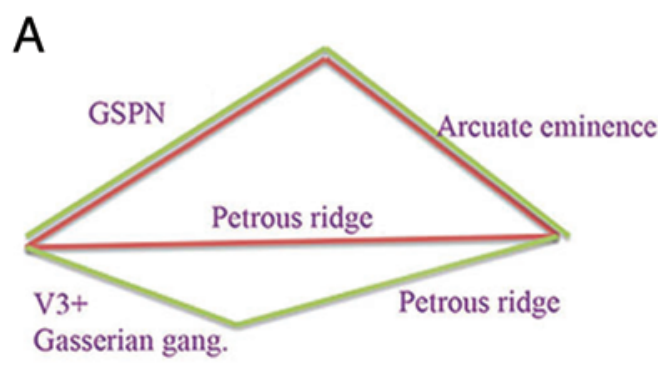

\section{Kawase's Triangle}

\section{MDK Rhomboid}
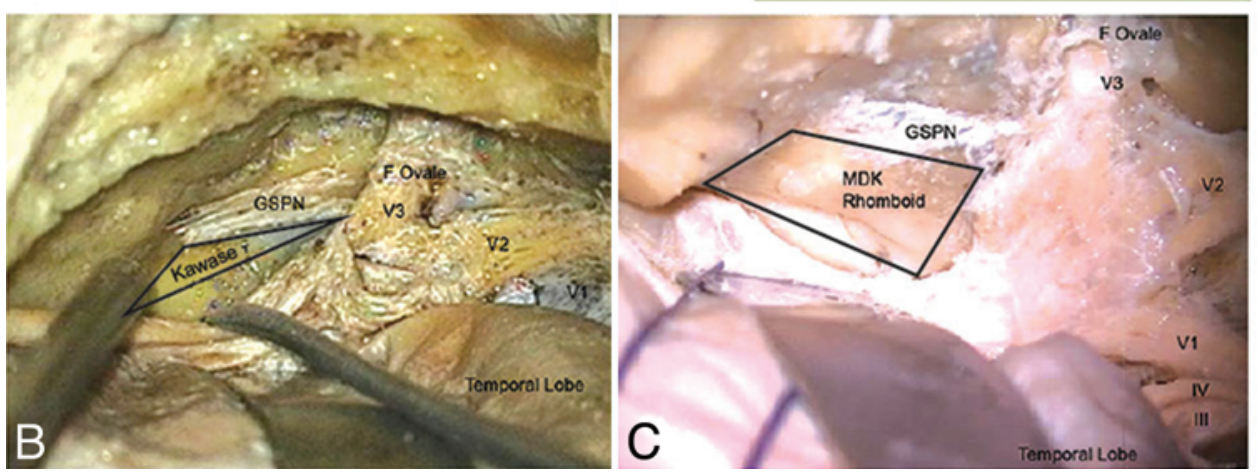

FIG. 2. A: Bony landmarks for the Kawase triangle and MDK rhomboid. B and C: Surface landmarks showing comparative areas of the Kawase triangle $(\mathrm{B})$ and the MDK rhomboid $(\mathrm{C})$. F = foramen; III = CN III; VI = CN VI; V1, V2, and V3 = ophthalmic, maxillary, and mandibular divisions of the trigeminal nerve. Figure is available in color online only. 
TABLE 2. Area and volume of Kawase's triangle and MDK rhomboid

\begin{tabular}{ccrccc}
\hline \multirow{2}{*}{$\begin{array}{c}\text { Specimen } \\
\text { No. }\end{array}$} & \multicolumn{2}{c}{ Drilled Kawase's Triangle } & & \multicolumn{2}{c}{ Drilled MDK Rhomboid } \\
\cline { 2 - 3 } \cline { 5 - 6 } & Area $\left(\mathrm{mm}^{2}\right)$ & Vol $\left(\mathrm{mm}^{3}\right)$ & & Area $\left(\mathrm{mm}^{2}\right)$ & Vol $\left(\mathrm{mm}^{3}\right)$ \\
\hline 1 & 194.55 & 673.548 & & 363.41 & 1505.238 \\
\hline 2 & 136.71 & 484.006 & & 333.25 & 1159.905 \\
\hline 3 & 188.63 & 555.779 & & 333.50 & 1106.166 \\
\hline 4 & 296.14 & 853.228 & & 406.64 & 1299.283 \\
\hline 5 & 256.73 & 795.969 & & 278.93 & 952.328 \\
\hline 6 & 304.10 & 1338.648 & & 532.73 & 1779.942 \\
\hline 7 & 287.32 & 791.765 & & 471.99 & 1468.305 \\
\hline 8 & 426.15 & 1078.588 & 614.28 & 1837.761 \\
\hline 9 & 373.75 & 764.162 & & 464.24 & 1440.275 \\
\hline 10 & 251.90 & 742.198 & 336.26 & 1115.321 \\
\hline 11 & 224.71 & 662.086 & 382.94 & 1270.151 \\
\hline 12 & 289.32 & 852.452 & 378.85 & 1256.585 \\
\hline Mean & 269.13 & 666.614 & 408.09 & 1349.272 \\
\hline
\end{tabular}
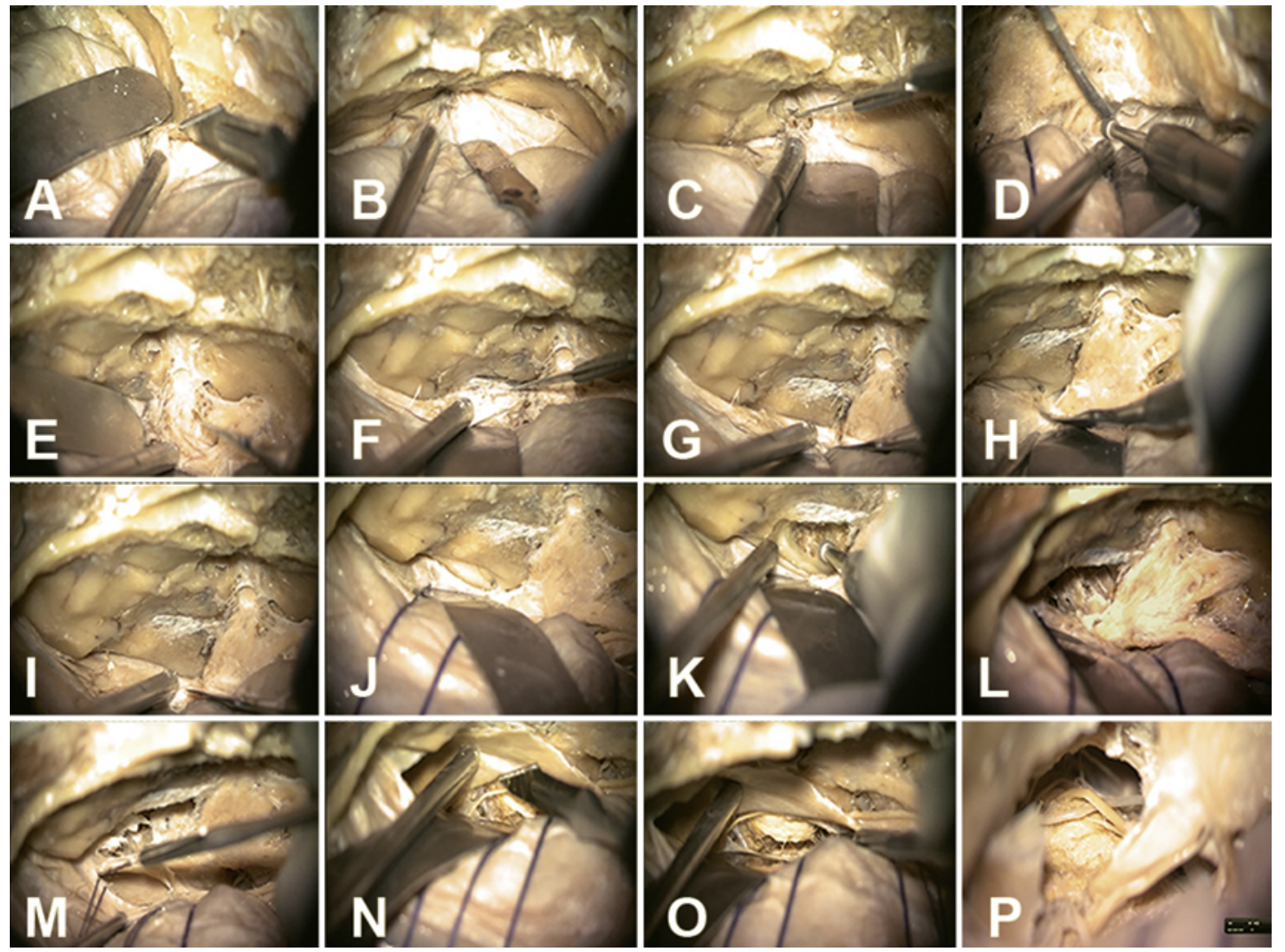

FIG. 3. Operative surgical steps for the MDK approach. A: Sacrifice of the orbitomeningeal artery at the middle cranial fossa floor. B: Extradural dissection of the temporal dura. C: Sacrifice of the MMA at the foramen spinosum. D: Orbital deroofing via an extradural anterior clinoidectomy. E: Interdural dissection at the lateral wall of the cavernous sinus. F: Sharp dissection over the greater superficial petrosal nerve. G: Exposure of the trigeminal nerve after interdural dissection. H: Exposure of the MDK rhomboid. I: Medial mobilization of the mandibular division of the trigeminal nerve (V3). J: Exposed rhomboid after mobilization of the gasserian ganglion. K: Drilling over the MDK rhomboid. L: Exposure of the posterior fossa dura. M: Opening of temporal dura. N: Division of tentorial dura behind trochlear nerve. O: Division of the superior petrosal sinus. P: Exposure of the posterior cranial fossa. Figure is available in color online only. 
riorly. The zygomatic osteotomy was performed from the lateral margin of the orbit anteriorly to the temporomandibular joint posteriorly. Removing part of the zygoma reduces the degree of temporal lobe retraction and allows a superiorly angled approach beneath the temporal lobe. (Although a zygomatic osteotomy is not done in traditional Kawase's approach, ${ }^{16}$ we added it for standardization in both procedures.) 3) The temporal base and sphenoid ridge were drilled to the middle cranial fossa floor until the orbitomeningeal artery (Fig. 3A). The temporal dura was elevated from the posterior-to-anterior and lateral-to-medial directions (Fig. 3B). 4) Subtemporal extradural dissection was done with sacrifice of the middle meningeal artery (MMA) after drill dilation of the foramen spinosum (Fig. 3C and D). 5) A sharp incision with a No. 11 surgical knife was made on the outer wall of the lateral cavernous sinus, i.e., the dura propria (Fig. 3E). Interdural dissection (be- tween the membranous dura and dura propria) was performed on the lateral wall of the cavernous sinus, exposing 3 divisions of the trigeminal nerve, without violating the inner dural layer. 6) Sharp dissection was done along the inferior margin of the greater petrosal groove to preserve the GSPN (Fig. 3F and G). Interdural dissection exposed the trigeminal nerve from the superior orbital fissure anteriorly to the gasserian ganglion posteriorly (Fig. $3 \mathrm{H}$ and I). It facilitated additional medial mobilization of V3 exposing a larger rhomboid area (Fig. 3J). 7) Surface landmarks (i.e., the tegmen tympani, AE, and GSPN) were identified from lateral to medial. The boundaries of the MDK rhomboid were delineated. Drilling with a diamond drill in this area exposed a larger fenestration of $20 \times 18 \mathrm{~mm}$ (Fig. 3K and L). Drilling proceeded in a posterior direction with no neurovascular structure in its way. 8) The posterior fossa dura and temporal dura were cut along with division of the

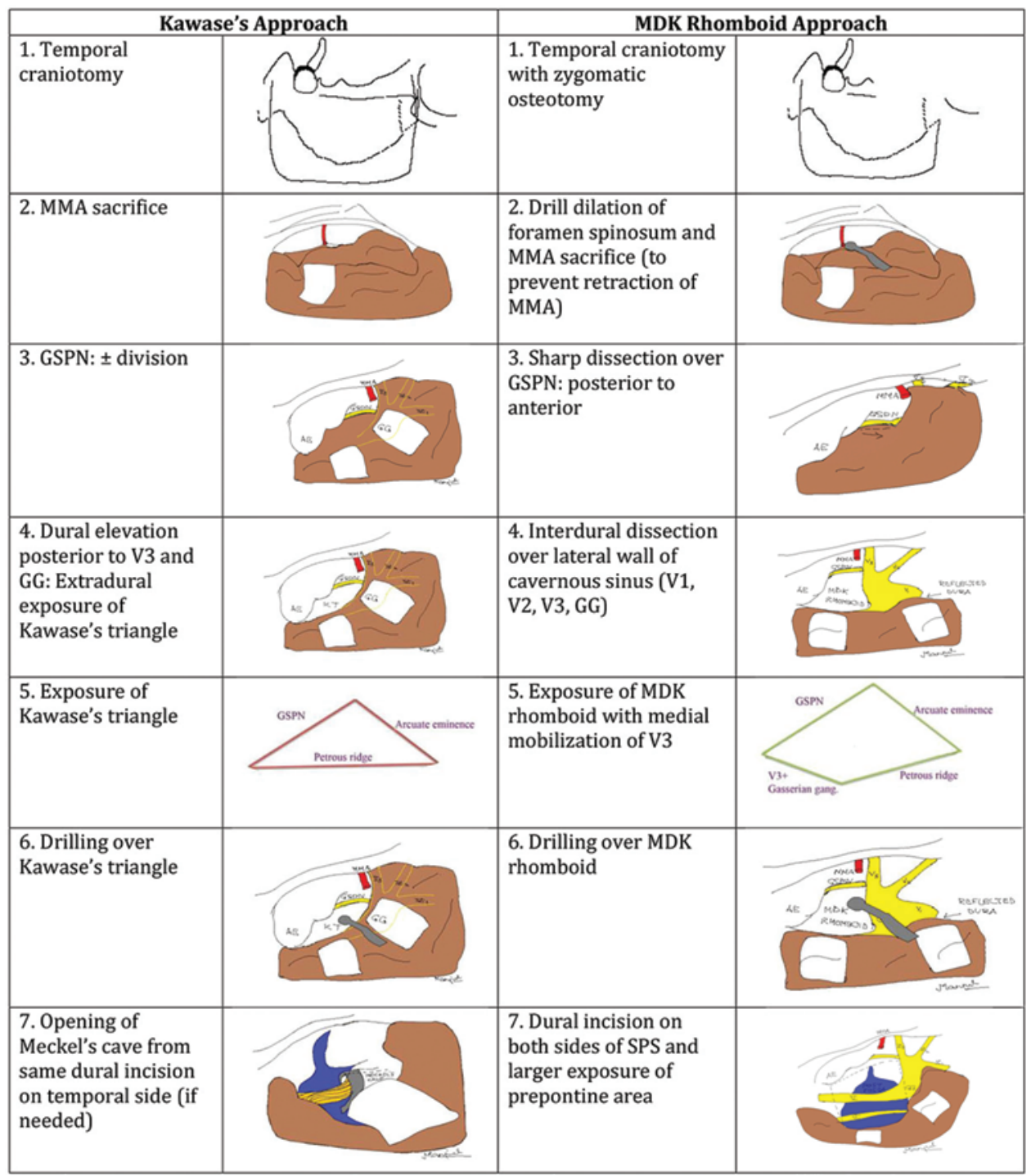

FIG. 4. Comparison of the Kawase and MDK approaches. $A E=$ arcuate eminence; gang. = ganglion; $G G$ = gasserian ganglion; GSPN = greater superficial petrosal nerve; KT = Kawase triangle; MMA = middle meningeal artery; SPS = superior petrosal sinus. Copyright Manjul Tripathi. Published with permission. Figure is available in color online only. 
superior petrosal sinus and tentorium, providing access to the infratentorial posterior cranial fossa (Fig. 3M and N). The exposure achieved extends from the basilar bifurcation superiorly to the CN VII/VIII complex inferiorly (Fig. $3 \mathrm{O}$ and $\mathrm{P})$.

\section{Custom Tailored MDK Rhomboid Approach}

For lesions extending into the anterior cavernous sinus and orbit, an extradural anterior clinoidectomy and frontotemporal zygomatic osteotomy with orbital deroofing may be added to the MDK approach (Video 2).

VIDEO 2. Custom-tailored addition of an extradural anterior clinoidectomy and orbital deroofing for the MDK approach. Copyright Ashish Suri. Published with permission. Click here to view with Media Player. Click here to view with Quicktime.

The lesser wing of the sphenoid was drilled from lateral to medial, and the tentorial duplicature was cut at the anterior clinoid process. Orbital deroofing was done, followed by an extradural anterior clinoidectomy (Fig. 3D) and anterolateral cavernous dissection through the far-lateral and Parkinson triangles. This exposure provides access to lesions extending into the anterior part of the cavernous sinus, from the superior orbital fissure anteriorly to the gasserian ganglion posteriorly.

\section{Results}

\section{Volumetric Analysis: Dry Temporal Bones}

The average lengths of the edges of Kawase's triangle of the dry temporal bones were $21.71 \pm 0.79 \mathrm{~mm} \times 17.11 \pm$ $0.40 \mathrm{~mm} \times 13.05 \pm 1.01 \mathrm{~mm}$. With the traditional Kawase approach, a triangle was obtained at the anterior petrous apex of the area ranging from $136.71 \mathrm{~mm}^{2}$ to $426.15 \mathrm{~mm}^{2}$ (mean $269.13 \mathrm{~mm}^{2}$ ). The corresponding volume of drilled bone ranged from $484.01 \mathrm{~mm}^{3}$ to $1338.65 \mathrm{~mm}^{3}$ (mean $666.614 \mathrm{~mm}^{3}$ ).

The average lengths of the margins of the rhomboid with the MDK approach were $13.15 \pm 0.84 \mathrm{~mm} \times 24.53$ $\pm 1.77 \mathrm{~mm} \times 12.54 \pm 0.94 \mathrm{~mm} \times 14.69 \pm 1.16 \mathrm{~mm}$. The area of the rhomboid was 278.93 to $614.28 \mathrm{~mm}^{2}$ (mean $408.09 \mathrm{~mm}^{2}$ ), and the corresponding volume was 952.328 to $1837.761 \mathrm{~mm}^{3}$ (mean $1349.272 \mathrm{~mm}^{3}$ ). The areas and volumes obtained by MDK rhomboid exposure were 1.5 times and 2 times larger, respectively, than those obtained with the traditional Kawase approach, which was statistically significant $(\mathrm{p}<0.001)$ (Table 2$)$.

\section{Exposed Area With Direction of Drilling: Cadaver Dissection}

The MDK approach provided a fenestration of $20 \times 18$ $\mathrm{mm}$ at the anterior petrous apex, which was significantly larger than fenestration achieved using the Kawase approach $(10 \times 5 \mathrm{~mm})$. Medial mobilization of $\mathrm{V} 3$ provided increased extension with significant surgical freedom at the Dorello canal and CN VI maneuverability. Interdural dissection and medial mobilization of the trigeminal nerve helps in lesser retraction over the temporal lobe. The added advantages are greater surgical freedom with increased anterolateral angulation (Figs. 3-5).

\section{Clinical Application}

For the last decade we have surgically treated all vari-

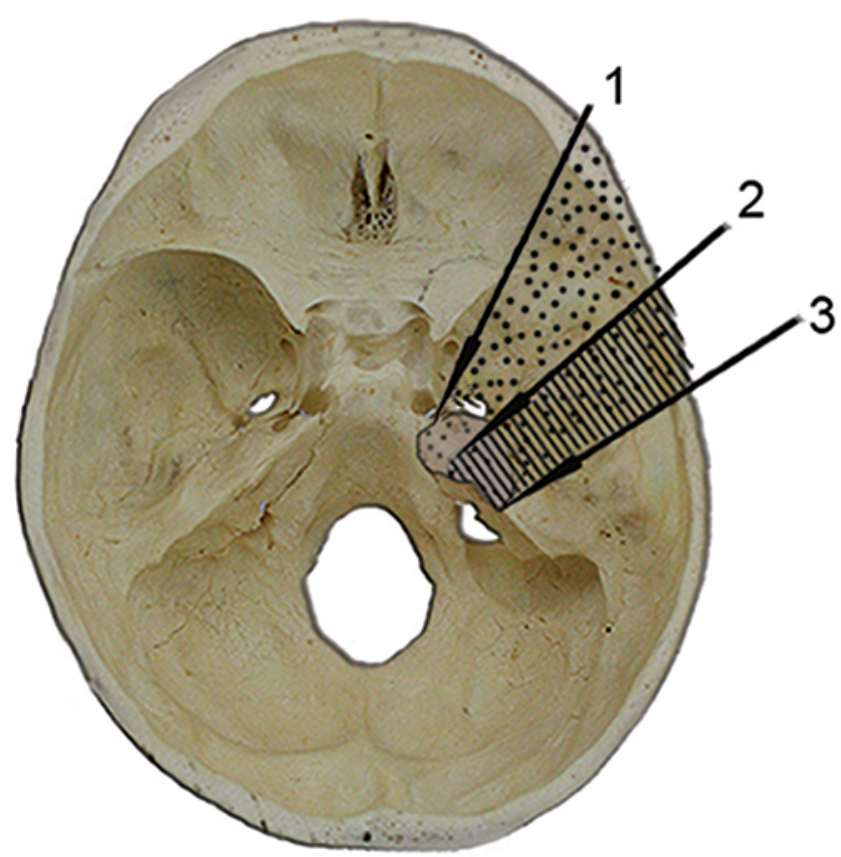

FIG. 5. Comparative view of the area exposed at the anterior petrous apex and anteroposterior angulation obtained with the MDK approach (dotted area between Arrows 1 and 3 ) and traditional Kawase approach (hatched area between Arrows 2 and 3). Figure is available in color online only.

eties of middle cranial fossa pathologies using the MDK approach. ${ }^{10}$ We prefer this technique because of its better angulation and exposure, which allow increased surgical ease (Fig. 6).

\section{Discussion}

The anterior petrous apex has been considered as a gateway to the posterior cranial fossa. Walter Dandy must be pleased to see that after decades of practice, the radical approach of aggressive skull base procedures has forced the surgical fraternity to change the philosophy to access lesions of the petroclival region. However, the aim remains the same (i.e., maximum removal with minimal morbidity). The middle cranial fossa approach was introduced by House et al. for vestibular nerve section in cases of intractable vertigo. ${ }^{15}$ It is beyond doubt that advances in microneurosurgical techniques, better magnification, and instrumentation have improved the margin of safety for approaching lesions in the sphenopetroclival and prepontine regions. ${ }^{3}$ After the modification of House et al., several modifications followed, with slight variations to the approaches, skull base dissections, and preservation of the vestibulocochlear apparatus. ${ }^{4}$ The need for better exposure in this region remains obvious, as the brainstem cannot be retracted and $\mathrm{CNs}$ do not tolerate excessive manipulation. ${ }^{20}$

\section{Comparison With Other Surgical Approaches to the Petroclival Region}

The Kawase approach provides access to traditionally difficult lesions, such as large sphenopetroclival meningiomas and basilar trunk aneurysms. This technically de- 


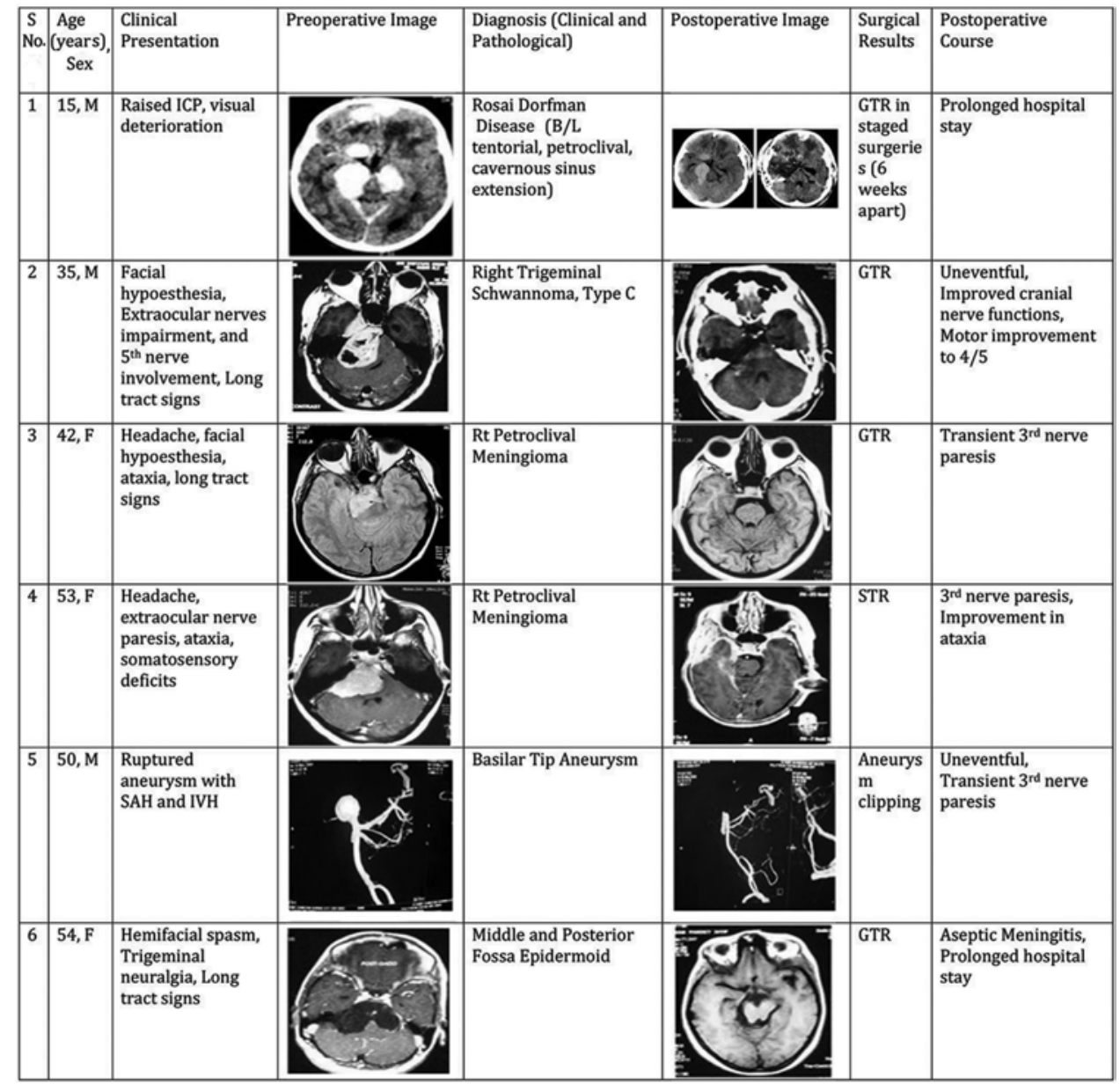

FIG. 6. Clinical details in 6 patients who underwent surgery via the MDK approach. $B / L=$ bilateral; GTR = gross-total resection; $\mathrm{ICP}=$ intracranial pressure; IVH = intraventricular hemorrhage; SAH = subarachnoid hemorrhage; STR = subtotal resection. Images in Cases 2, 4, and 5, copyright Ashish Suri. Published with permission.

manding procedure is popular because of the surgeon's familiarity with anatomy, years of successful practice, lesser parenchymal injuries, and temporal lobe retraction. With it, we get a triangular area at the petroclival region, medial to the internal auditory canal devoid of any significant neurovascular structures (Table 3). ${ }^{3,7,16,17}$ The fenestration of $10 \times 5 \mathrm{~mm}$ sometimes proves insufficient for lesions with significant infratentorial and cavernous sinus extension. Individual temporal bones suffer from significant variability in morphometric parameters. Earlier studies have raised questions regarding the value of the Kawase approach; the size of the window in the petrous bone is significantly smaller, providing insufficient space as a corridor to the posterior fossa. ${ }^{7}$ Only a few authors have performed and described morphometric analyses of these approaches. $3,6,7,14,19$

The tip of the petrous apex lies hidden under the lateral margin of the gasserian ganglion. Interdural dissection on the lateral wall of the cavernous sinus allows a wider area of exposure with some degree of medial mobilization of V3, which helps in better exposure of the pathological lesion. With added surgical exposure by the MDK approach, we get a larger fenestration due to removal of this hidden tip of the petrous apex. This provides increased surgical access to CN VI at the Dorello canal, the upper two-thirds of the clivus, and the prepontine area (exposure of CNs IIVIII). We call this approach the modified Dolenc-Kawase approach, as it is an addition of the Dolenc approach (anterolateral cavernous dissection $)^{8}$ to the Kawase approach (extradural subtemporal transtentorial approach) and provides a larger area at the anterior petrous apex. ${ }^{16,17}$ Anterior clinoidectomy and orbital deroofing are additional custom-tailored procedures with the MDK approach for lesions extending into the interpeduncular and suprasellar cisterns, orbit, oculomotor trigone, and cavernous sinus. An anterior clinoidectomy and a complete transcavernous approach significantly increase the working area and linear exposure of the basilar artery compared with abbreviated forms of the approach $(\mathrm{p}<0.05){ }^{9}$

\section{Clinical Implications of MDK Rhomboid Geometry in Comparison With the Kawase Triangle}

Lesions at the petrous apex are notorious for expanding in every possible direction, namely the middle cranial fossa, para cavernous sinus, orbit, and posterior cranial fossa. Before Kawase introduced his approach, all middle fossa 
TABLE 3. Comparison of various surgical techniques for petroclival region

\begin{tabular}{|c|c|c|c|c|}
\hline Authors \& Year & $\begin{array}{l}\text { Procedure } \\
\text { Performed }\end{array}$ & $\begin{array}{l}\text { Fenestration } \\
\text { at Petrous } \\
\text { Apex }\end{array}$ & Pros & Remarks \\
\hline $\begin{array}{l}\text { Kawase et al., } \\
\text { 1985; Kawase } \\
\text { et al., 1991; } \\
\text { Day et al., } \\
1994\end{array}$ & $\begin{array}{l}\text { Subtemporal extra- } \\
\text { dural transtento- } \\
\text { rial approach }\end{array}$ & $10 \times 5 \mathrm{~mm}$ & $\begin{array}{l}\text { 1) Straight access to anterior petrous; 2) familiar- } \\
\text { ity among neurosurgeons }\end{array}$ & $\begin{array}{l}\text { 1) Traction to GSPN; 2) potential risk to } \\
\text { vein of Labbé, cochlea, semicircular } \\
\text { canals \& ICA; 3) nontailored approach }\end{array}$ \\
\hline $\begin{array}{l}\text { Hakuba et al., } \\
1988\end{array}$ & $\begin{array}{l}\text { Combined retroau- } \\
\text { ricular preauricu- } \\
\text { lar transpetrosal } \\
\text { transtentorial } \\
\text { approach }\end{array}$ & $10 \times 5 \mathrm{~mm}$ & $\begin{array}{l}\text { 1) Extradural exposure of petrous bone; 2) } \\
\text { minimal retraction injury to temporal lobe \& } \\
\text { cerebellum }\end{array}$ & $\begin{array}{l}\text { 1) Needs radical mastoidectomy \& } \\
\text { extensive bone removal; 2) sinus injury; } \\
\text { 3) increased operative time; 4) risk of } \\
\text { hearing impairment }\end{array}$ \\
\hline $\begin{array}{l}\text { Harsh \& Sekhar, } \\
\text { 1992; Day et } \\
\text { al., } 1994\end{array}$ & $\begin{array}{l}\text { Subtemporal an- } \\
\text { terior intradural } \\
\text { transcavernous } \\
\text { approach }\end{array}$ & $10 \times 15 \mathrm{~mm}$ & $\begin{array}{l}\text { 1) Lesser chances of injury to petrous ICA by } \\
\text { intradural drilling; 2) larger fenestration }\end{array}$ & $\begin{array}{l}\text { 1) Resection of anterior } 4 \mathrm{~cm} \text { of inferior } \\
\text { temporal gyrus (optional); } 2 \text { ) needs du- } \\
\text { ral closure at skull base; } 3 \text { ) dissection } \\
\text { of posterolateral cavernous sinus; 4) } \\
\text { needs division \& resuturing of trigemi- } \\
\text { nal nerve; } 5 \text { ) injury to vein of Labbé }\end{array}$ \\
\hline $\begin{array}{l}\text { Gupta \& } \\
\quad \text { Salunke, } 2012\end{array}$ & $\begin{array}{l}\text { Transsylvian intra- } \\
\text { dural anterior } \\
\text { petrosectomy }\end{array}$ & $\begin{array}{l}\text { Custom } \\
\text { tailored }\end{array}$ & $\begin{array}{l}\text { 1) Tailored bone removal as per the lesion; 2) } \\
\text { no pressure or traction on vein of Labbé; } 3 \text { ) } \\
\text { early control of tumor vascularity; 4) tumors w/ } \\
\text { orbital extension can also be removed }\end{array}$ & $\begin{array}{l}\text { 1) Needs FTOZ craniotomy; 2) needs me- } \\
\text { ticulous dural closure at skull base; } 3 \text { ) } \\
\text { potential need to sacrifice transsylvian } \\
\text { temporal bridging veins }\end{array}$ \\
\hline $\begin{array}{l}\text { Gupta et al., } \\
2006\end{array}$ & $\begin{array}{l}\text { MDK approach for } \\
\text { subtemporal } \\
\text { transcavernous } \\
\text { extradural an- } \\
\text { terior petrosec- } \\
\text { tomy }\end{array}$ & $20 \times 18 \mathrm{~mm}$ & $\begin{array}{l}\text { 1) Larger fenestration at anterior petrous apex; } \\
\text { 2) straight approach to petrous apex; 3) surgi- } \\
\text { cal freedom at Dorello canal \& prepontine } \\
\text { space; 4) no dural breach; 5) lesser temporal } \\
\text { retraction; 6) custom tailored for lesions in } \\
\text { cavernous sinus \& orbital extension }\end{array}$ & $\begin{array}{l}\text { 1) Optional anterior clinoidectomy \& } \\
\text { transcavernous exposure; } 2 \text { ) needs } \\
\text { mobilization of } \mathrm{V} 3 ; 3) \text { increased opera- } \\
\text { tive time ( } 30 \text { mins) }\end{array}$ \\
\hline
\end{tabular}

FTOZ = frontotemporo-orbito-zygomatic; ICA = internal carotid artery.

approaches, such as the subtemporal transtentorial approach, were associated with complications, such as temporal lobe retraction injuries, especially venous infarcts. ${ }_{3,7,10}$ With the MDK approach, we were able to create an area larger than that described by Kawase by removing bone from the AE to the tip of the petrous apex, which unroofs the internal auditory canal $270^{\circ}$ and increases surgical freedom.

Although it is clear that the exposure obtained is much greater than that obtained with the Kawase approach, the major determinants of tumor resection with preservation of critical structures is also determined by tumor consistency, arachnoid plane preservation, and degree of involvement of critical neurovascular structures. ${ }^{3}$ The senior author (A.S.) has practiced the MDK approach and has not encountered any retraction-related injury to temporal lobes. There were transient $\mathrm{CN}$ deficits in the postoperative period; otherwise, the complication rates were comparable with those associated with the Kawase approach, with increased surgical exposure and ease (Fig. 6)

\section{Conclusions}

The present paper describes a new technical modification of the traditional Kawase approach. Skull base procedures are complex and demand high competence and proficiency by the treating surgeon. Extent, pathology, and preoperative neurological status of the patient guide the surgeon in choosing the appropriate approach. An ideal approach is one that provides maximum exposure with minimal bone dissection and injury to parenchyma and neurovascular structures. There is little space for tailored approaches for lesions in the petroclival region. The MDK approach is a custom-tailored extradural approach for middle cranial fossa lesions with variable extension into the anterior and posterior cranial fossae.

The complexities of the skull base anatomy and dissection must be understood in cadavers in the laboratory before the approaches are practiced in the operation room. In our report, cadaveric analysis is a validating factor to prove our volumetric findings. The contribution of our study is primarily in describing our philosophy of a larger exposed area at the anterior petrous apex with an entirely extradural approach that provides enhanced exposure of middle cranial fossa lesions for better excision.

\section{Acknowledgments}

We would like to acknowledge the efforts of technical and application specialists from the Neurosurgery Skills Training Facility, Neurosurgery Education and Training School, All India Institute of Medical Sciences, New Delhi, India. We thank Mr. 
Subhas Bora, Mr. Ajab Singh, Mr. Ram Niwas, Mr. Shashi Shekhar, Mr. Trivendra Yadav, Mr. Gaurav Bhardwaj, Mr. Aakash Sharma, Mr. Suresh Kothari, Mr. Vikram Singh, and Mr. Satish Kumar for their untiring valuable support.

\section{References}

1. al-Mefty O, Anand VK: Zygomatic approach to skull-base lesions. J Neurosurg 73:668-673, 1990

2. al-Mefty O, Ayoubi S, Smith RR: The petrosal approach: indications, technique, and results. Acta Neurochir Suppl (Wien) 53:166-170, 1991

3. Bambakidis NC, Kakarla UK, Kim LJ, Nakaji P, Porter RW, Daspit CP, et al: Evolution of surgical approaches in the treatment of petroclival meningiomas: a retrospective review. Neurosurgery 62 (6 Suppl 3):1182-1191, 2008

4. Bernardo A, Kim HK, Zabramski JM, Passacantilli E, Deshmukh P, Spetzler RF: A functional sparing "conservative" perilabyrinthine-transpetrosal approach to the anterior brain stem and clivus. American Association of Neurological Surgeons. (Abstract) (http://www.aans.org/Media/ Article.aspx?ArticleID=17821) [Accessed February 4, 2015]

5. Bochenek Z, Kukwa A: An extended approach through the middle cranial fossa to the internal auditory meatus and the cerebello-pontine angle. Acta Otolaryngol 80:410-414, 1975

6. Chang SW, Wu A, Gore P, Beres E, Porter RW, Preul MC, et al: Quantitative comparison of Kawase's approach versus the retrosigmoid approach: implications for tumors involving both middle and posterior fossae. Neurosurgery 64 (3 Suppl):ons44-ons52, 2009

7. Day JD, Fukushima T, Giannotta SL: Microanatomical study of the extradural middle fossa approach to the petroclival and posterior cavernous sinus region: description of the rhomboid construct. Neurosurgery 34:1009-1016, 1994

8. Dolenc VV: Frontotemporal epidural approach to trigeminal neurinomas. Acta Neurochir (Wien) 130:55-65, 1994

9. Figueiredo EG, Zabramski JM, Deshmukh P, Crawford NR, Preul MC, Spetzler RF: Anatomical and quantitative description of the transcavernous approach to interpeduncular and prepontine cisterns. Technical note. J Neurosurg 104:957964, 2006

10. Gupta DK, Suri A, Mahapatra AK, Mehta VS, Garg A, Sarkar C, et al: Intracranial Rosai-Dorfman disease in a child mimicking bilateral giant petroclival meningiomas: a case report and review of literature. Childs Nerv Syst 22:11941200,2006

11. Gupta SK, Salunke P: Intradural anterior petrosectomy for petroclival meningiomas: a new surgical technique and results in 5 patients: technical note. J Neurosurg 117:10071012,2012

12. Hakuba A, Nishimura S, Jang BJ: A combined retroauricular and preauricular transpetrosal-transtentorial approach to clivus meningiomas. Surg Neurol 30:108-116, 1988

13. Harsh GR IV, Sekhar LN: The subtemporal, transcavernous, anterior transpetrosal approach to the upper brain stem and clivus. J Neurosurg 77:709-717, 1992

14. Horgan MA, Anderson GJ, Kellogg JX, Schwartz MS, Spektor S, McMenomey SO, et al: Classification and quantification of the petrosal approach to the petroclival region. J Neurosurg 93:108-112, 2000
15. House WF, Hitselberger WE, Horn KL: The middle fossa transpetrous approach to the anterior-superior cerebellopontine angle. Am J Otol 7:1-4, 1986

16. Kawase T, Shiobara R, Toya S: Anterior transpetrosaltranstentorial approach for sphenopetroclival meningiomas: surgical method and results in 10 patients. Neurosurgery 28:869-876, 1991

17. Kawase T, Toya S, Shiobara R, Mine T: Transpetrosal approach for aneurysms of the lower basilar artery. J Neurosurg 63:857-861, 1985

18. Sakata S: Microsurgical anatomy of the basilar artery: surgical approaches to the basilar trunk and vertebrobasilar junction aneurysms. Kor J Cerebrovasc Dis 3:5-10, 2001

19. Samii M, Ammirati M: The combined supra-infratentorial pre-sigmoid sinus avenue to the petro-clival region. Surgical technique and clinical applications. Acta Neurochir (Wien) 95:6-12, 1988

20. Sincoff EH, Delashaw JB: Editorial. Petroclival surgery. J Neurosurg 104:4-6, 2006

21. Siwanuwatn R, Deshmukh P, Figueiredo EG, Crawford NR, Spetzler RF, Preul MC: Quantitative analysis of the working area and angle of attack for the retrosigmoid, combined petrosal, and transcochlear approaches to the petroclival region. J Neurosurg 104:137-142, 2006

22. Sugita K, Kobayashi S, Takemae T, Tada T, Tanaka Y: Aneurysms of the basilar artery trunk. J Neurosurg 66:500-505, 1987

\section{Author Contributions}

Conception and design: Suri. Acquisition of data: Tripathi, Deo. Analysis and interpretation of data: Suri, Tripathi, Deo, Srivastav, Baby, Prasad, Paul. Drafting the article: Tripathi. Critically revising the article: Suri, Tripathi, Prasad. Reviewed submitted version of manuscript: Deo. Statistical analysis: Tripathi, Srivastav, Baby. Administrative/technical/material support: Suri, Kumar, Kalra, Banerjee, Prasad, Paul, Roy, Lalwani. Study supervision: Suri, Kalra, Banerjee, Roy, Lalwani.

\section{Supplemental Information Videos}

Video 1, Media Player. http://mfile.akamai.com/21490/wmv/ digitalwbc.download .akamai.com/21492/wm.digitalsource-naregional/jns13-2876_video_1.asx.

Video 1, Quicktime. http://mfile.akamai.com/21488/mov/ digitalwbc.download.akamai.com/21492/qt.digitalsource-global/ jns13-2876_video_1.mov.

Video 2, Media Player. http://mfile.akamai.com/21490/wmv/ digitalwbc.download.akamai.com/21492/wm.digitalsource-naregional/jns13-2876_video_2.asx.

Video 2, Quicktime. http://mfile.akamai.com/21488/mov/ digitalwbc.download.akamai.com/21492/qt.digitalsource-global/ jns13-2876_video_2.mov.

\section{Correspondence}

Ashish Suri, Department of Neurosurgery, All India Institute of Medical Sciences, CNC, AIIMS, Ansari nagar, New Delhi 110029, India. email: surineuro@gmail.com. 